\title{
CAPÍTULO 52: RISCO SANITÁRIO NA COMERCIALIZAÇÃO DE CARNE: CONDIÇÕES ESTRUTURAIS DO MERCADO FRANCISCO BOLONHA, BELÉM
} $(\text { PA })^{1}$

\section{CHAPTER 52: HEALTH RISK IN THE MEAT MARKETING: STRUCTURAL CONDITIONS OF THE FRANCISCO BOLONHA MARKET, BELÉM (PA)}

\author{
Matheus Yuri de Oliveira Rosa²; Vitória Nazaré Costa Seixas ${ }^{3}$
}

\begin{abstract}
Resumo
Esta pesquisa objetivou avaliar as condições estruturais e higiênico-sanitárias do Mercado de Carne Francisco Bolonha, no Complexo do Ver-o-Peso, Belém (PA), a fím de verificar se o local apresenta requisitos adequados para a comercialização de alimentos, conforme a exigência dos instrumentos normativos em vigência no Brasil. Para tanto, foi realizada pesquisa de campo mediante a utilização de diferentes instrumentos coleta dos dados, a saber: observações sistemáticas, registros fotográficos, entrevista e aplicação de uma lista de verificação (checklist) com a Administração do mercado. Este último instrumento foi estruturado em 30 quesitos organizados em 4 itens, baseados na Portaria 386/1997, na RDC 275/2002, na RDC 216/2004 e na Portaria 2619/2011. Os resultados, embora demonstrem que o Mercado apresenta "Boa" avaliação, evidenciam desconformidades em relação à água, aos balcões, às vedações de portas etc. Tais inadequações para o comércio e para a manipulação de alimentos contribuem para conformar um espaço propício à contaminação e à disseminação de Doenças Veiculadas por Alimentos (DVAs).
\end{abstract}

Palavras-Chave: Condições higiênico-sanitárias, Mercado Público, Ver-o-Peso.

\begin{abstract}
This research aimed to assess the structural, sanitary and hygienic conditions of the Francisco Bolonha Meat Market, at the Ver-o-Peso complex, in Belém (in the state of Pará/Brazil). It was made in order to verify whether the site presents adequate condition for food marketing, as per requirement of Brazil's legal instruments. For this purpose, a field research was made using diverse data colletion instruments, such as: systematic observations, photographic records, interviews, and a check-list application for the Market Manegement to respond. The latter instrument was instructured in 30 requirements organized in 4 items, based on the Ordinance 386/1997, the Collegiate Directorate Resolution (RDC) 275/2002, the RDC 216/2004, and the Ordinance 2619/2011. Although the results show that the Market has "Good" evaluation, they also evince noncompliance in relation to the water, the counters, the door sealings, etc. Such inadequacies to the market and handling of food contribute to set a space which is conductive to contamination and dissemination of Foodborne Diseases (DVAs).
\end{abstract}

Keywords: Sanitary and Hygienic conditions, Public Market, Ver-o-Peso.

\footnotetext{
${ }^{1}$ Artigo referente aos dados parciais do Projeto de Pesquisa "Análise do risco sanitário de carne bovina comercializada no Mercado Francisco Bolonha, Belém (PA)", com financiamento do CNPq.

${ }^{2}$ Acadêmico de Tecnologia de Alimentos, Universidade do Estado do Pará (UEPA), matheusyurid@ gmail.com;

${ }^{3}$ Doutora em Ciência e Tecnologia de Alimentos, docente da Universidade do Estado do Pará (UEPA), vitoria.seixas@uepa.br.
} 


\section{Introdução}

No Brasil, diversos estudos (MATOS et al., 2015; COSTA et al., 2017; ROSA et al., 2019) têm apontado que, entre os locais de comercialização de carne bovina, as feiras livres e os mercados populares compreendem os ambientes mais propício à contaminação. A carne bovina, pois, é um alimento deveras perecível e suscetível à veiculação de doenças em face de suas características nutricionais, uma vez que é rica em nutrientes necessários para o crescimento de bactérias, leveduras e bolores. Afinal, cortada e/ou moída, a carne bovina vendida nesses espaços é caracterizada como uma das principais geradoras e potencializadoras de infecções em humanos, dado o seu consumo acentuado, as condições de manipulação por parte dos vendedores e as precárias infraestruturas dos locais de armazenamento e de comercialização (REIS, 2019).

Diante disso, segundo Rosa et al. (2019), os consumidores têm se mostrado preocupados com a qualidade da carne consumida, se tornando mais informados e exigentes, logo, primando por produtos de maior qualidade, isto é, alimentos livres de agentes que atentem contra a saúde humana. Por assim ser, a carne bovina demanda cuidados especiais durante o processo produtivo de forma a garantir a sua qualidade e a saúde do consumidor (OLIVEIRA et al., 2017). A final, conquanto seja oriunda de animais sadios, a qualidade da carne não depende apenas da microbiota natural, de contaminantes patogênicos ou deterioradores, mas também da higiene no processo produtivo e beneficiador (REIS, 2019). Nesse cenário, as condições estruturais e higiênico-sanitárias dos locais de comercialização, como feiras e mercados populares, têm uma relevância significativa para a manutenção da qualidade da carne (RODRIGUES et al., 2017).

Nesse contexto, no Brasil, foram criados instrumentos normativos para controlar e assegurar a comercialização de alimentos em condições adequadas. Entre tais normas, pode-se destacar a RDC 275/2002 - que dispõe sobre o Regulamento Técnico de Procedimentos Operacionais Padronizados aplicados aos Estabelecimentos Produtores/Industrializadores de Alimentos e apresenta a lista de verificação das boas práticas (BRASIL, 2002) - e a RDC 216/2004 - que estabelece procedimentos de Boas Práticas para serviços de alimentação objetivando garantir as condições higiênico-sanitárias dos alimentos (BRASIL, 2004). Destarte, as boas práticas de fabricação, manipulação e comercialização de alimentos são indispensáveis para a ineficiência dos processos de toda a cadeia de produção, visto que contribuem para a segurança, o controle de qualidade e a soberania alimentar (ROSA et al., 2019).

De posse destas compreensões, este trabalho emerge com o objetivo de avaliar as 
condições estruturais e higiênico-sanitárias do Mercado de Carne Francisco Bolonha, Belém (PA), a fim de verificar se o espaço está adequado para atuar na comercialização de alimentos, devido à sua importância sociocultural para a cidade. Cumpre destacar que o Bolonha foi eleito como lócus de estudo por figurar como o principal e mais popular espaço de comercialização de carne, pois está situado no Complexo do Ver-o-Peso.

\section{Material e Métodos}

\section{Área de estudo}

O Mercado de Carne Francisco Bolonha, que faz parte do Complexo do Ver-o-Peso, está localizado na Avenida Castilho França (a frente), entre as Travessas Oriental do Mercado e Ocidental do Mercado, e de fundos para a Rua 15 de Novembro, Bairro do Comércio. Atualmente, no térreo do mercado estão as lojas de acesso livre e independente das ruas que circundam o mercado e no interior os boxes individuais (Figura 1), que estão subdivididos em setores: venda de carne, refeições e artesanato, contando com a administração do local e uma escada helicoidal com acesso a um mirante (SILVA, 2018). No mais, é relevante ressaltar a importância do Bolonha como um importante polo de escoamento de produtos regionais, juntamente com o potencial produtivo das ilhas ao entorno da cidade e dos demais municípios (SILVA; CASTRO, 2013).

Figura 1. Planta do Mercado Francisco Bolonha

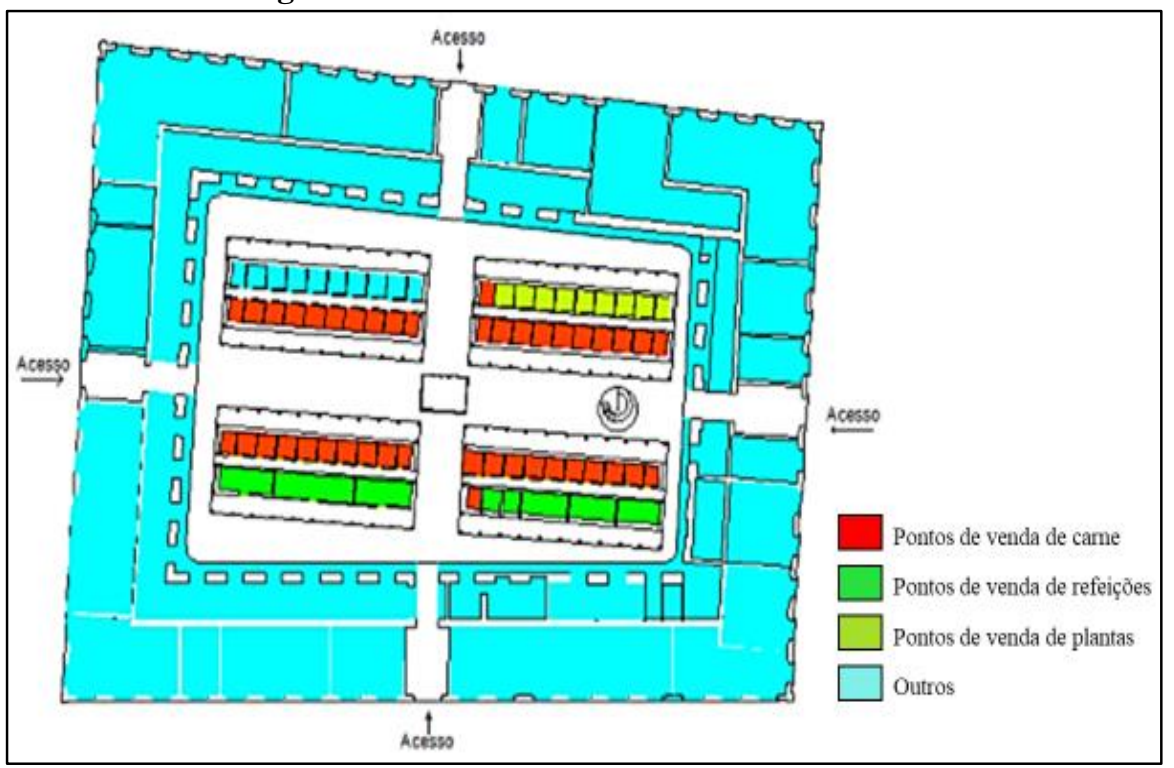

Fonte: Adaptado de Silva (2018).

\section{Coleta de dados}

A pesquisa de campo, ocorrida entre os dias 15 e 16 de janeiro de 2020, utilizou 
diferentes instrumentos para a coleta de dados, a saber: observação não participante, registro fotográfico, entrevista com a administração do mercado e aplicação de uma lista de verificação (check-list) relacionada às condições estruturais e higiênico-sanitárias, especificamente, do Mercado de carne Francisco Bolonha, no Complexo do Ver-o-Peso, Belém (PA).

O instrumento de coleta de dados contou com 30 quesitos distribuídos em 4 itens, que são: em 1) Água; 2) Controle integrado de pragas; 3) Sanitários e vestiários e; 4) Instalações e edificações do mercado. Sendo importante destacar que o check-list foi baseado nos seguintes instrumentos normativos: o Regulamento da inspeção Industrial e Sanitária de Produtos de Origem Animal, Portaria No 368/1997 (BRASIL, 1997); o Regulamento Técnico de Procedimentos Operacionais Padronizados aplicados aos Estabelecimentos Produtores/Industrializadores de Alimentos, Resolução-RDC No 275/2002 (BRASIL, 2002); o Regulamento Técnico de Boas Práticas para Serviços de Alimentação, Resolução-RDC $n^{\circ}$ 216/2004 (BRASIL, 2004); e o Roteiro de inspeção de açougues e peixarias, anexo da Portaria $n^{\circ}$ 2619/2011, da Prefeitura Municipal de São Paulo (SÃO PAULO, 2011). Não obstante, convém mencionar que a lista de verificação (check-list) considerou as condições culturais e de viabilidade econômica comuns às feiras e aos mercados públicos populares, mas sem deixar de exigir condições básicas de higiene e sanidade.

Diante disso, foram avaliados os requisitos que são exigidos pelas legislações citadas acima. As alternativas para assinalar o check list foram: 1) Sim (10 pts.) - quando o quesito não atendia ao item observado; 2) Parcialmente (5 pts.) - quando o quesito existia mas não atendia a conformidade; 3 ) Não (0 pts.) - quando o quesito não atendia ao item observado; 4) Não se aplica - quando o quesito não foi considerado pertinente ao local pesquisado e; 5) Não observado - quando o quesito não foi encontrado no local pesquisado. Para determinar o percentual de adequação dos pontos de venda do mercado às disposições legais, foi empregada a fórmula de conformidade baseada na RDC 275/2002 da Vigilância Sanitária (BRASIL, 2002), qual seja:

Conformidade $(\%)=$ Índice real x $100 /$ Total de requisitos observados

Após cálculos dos percentuais, a classificação da conformidade dos locais de venda foi realizada com base também nas instruções das Boas Práticas de Fabricação (BPF), da RDC 275/2002 (BRASIL, 2002), que englobam os requisitos mínimos pela legislação quanto à manipulação e à comercialização de alimentos, como mostra a Tabela 1. Assim sendo, foram considerados como "Ruim" os valores iguais e/ou abaixo de cinquenta por cento $(\leq 50 \%)$, foram 
classificados como "Bom" os valores que variaram de cinquenta e um a setenta e quatro por cento $(51 \%$ a $74 \%)$ e, por fim, considerou-se como "Excelente" os valores que variaram de setenta e cinco a cem por cento $(75 \%$ a $100 \%)$.

Tabela 1. Classificação do nível de conformidade dos pontos de venda

\begin{tabular}{ccc}
\hline Classificação & Conformidade (\%) & Situação \\
\hline Grupo 1 & De 75\% a 100\% & Excelente (E) \\
Grupo 2 & De 51\% a 74\% & Bom (B) \\
Grupo 3 & $\leq 50 \%$ & Ruim (R) \\
\hline
\end{tabular}

Fonte: Adaptado da RDC 275/2002 (BRASIL, 2002).

\section{Resultados e Discussão}

\section{Condições estruturais e higiênico-sanitárias do Mercado Francisco Bolonha}

A partir da obtenção dos dados, pôde-se observar que há um equilíbrio em relação as conformidades e as desconformidades, tendo em vista que a avaliação geral das condições estruturais e higiênico-sanitárias do Mercado Francisco Bolonha resultou em 58,33\% (Bom), do nível de conformidade com a legislação, conforme a Tabela 2. Apesar de ser um resultado incomum nos estudos que analisam mercados públicos e feiras populares pelo Brasil (SANTOS et al. 2016; RODRIGUES et al. 2017; COSTA et al. 2017; ROSA et al. 2019; REIS, 2019), estes dados são reflexo das recentes e recorrentes ações públicas no local, tendo em vista que, além de ser o principal e um dos mais antigo mercados de Belém, compõe o conjunto arquitetônico patrimonial do Complexo do Ver-o-Peso, tombado pelo IPHAN. Logo, por fazer parte do Cartão Postal Turístico da cidade, há um investimento maior por parte do Poder Público, diferente da situação destoante visualizada em outros mercados do município, como Rosa et al. (2019) constataram no Mercado do Distrito de Icoaraci, Belém (PA).

Tabela 2. Avaliação das condições estruturais e higiênico-sanitárias do Mercado Francisco Bolonha, Belém

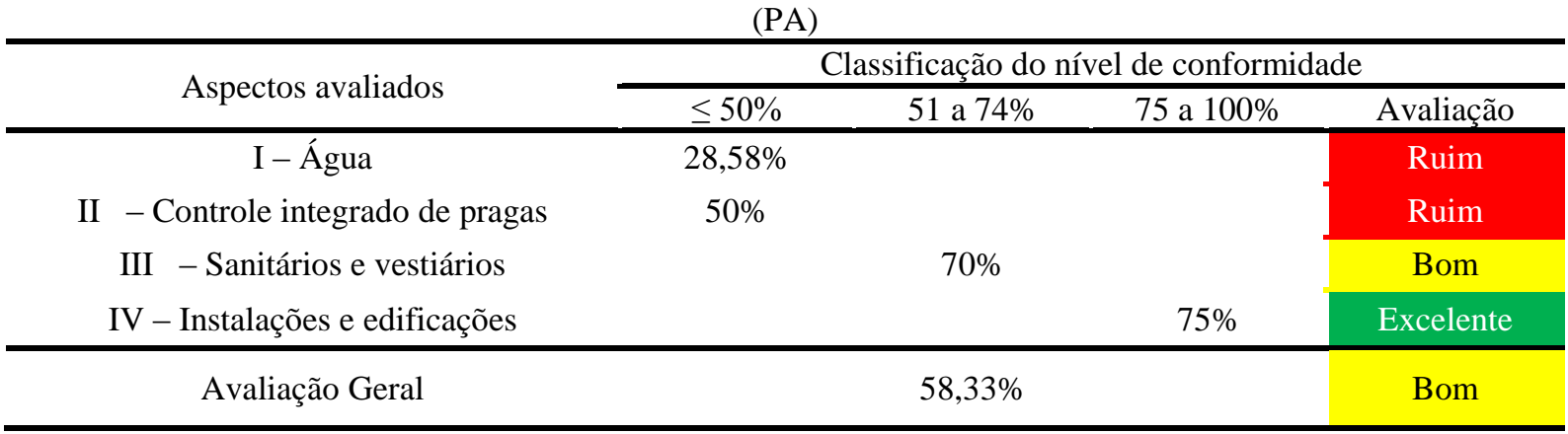

Fonte: Própria (2020). 
Acerca do item "1 - Água”, a avaliação alcançou 20 dos 70 pontos possíveis, o que corresponde a apenas $28,58 \%$ de conformidade (Tabela 3), sendo considerado pelos parâmetros de classificação da RDC 275/2002 (BRASIL, 2002) como "Ruim”. Embora disponha de água oriunda do abastecimento público e os reservatórios com boas condições de uso (dotados de tampa, livre de vazamentos, livre de infiltrações e descascamentos), o mercado não apresentava no momento da pesquisa nenhum dos demais quesitos, quais sejam: apropriada frequência de higienização do reservatório de água, existência de registros e/ou comprovantes de higienização do reservatório, laudos laboratoriais acerca da potabilidade da água, além do controle de potabilidade realizado por técnicos especializados.

Tabela 3. Aspectos avaliados referente ao abastecimento de água do mercado

\begin{tabular}{|c|c|c|c|}
\hline \multicolumn{2}{|l|}{ I - ÁGUA } & Pontuação & Resultado \\
\hline \multicolumn{2}{|c|}{ 1) A água utilizada é de abastecimento público; } & 10 & Conforme \\
\hline \multicolumn{2}{|c|}{ 2) O mercado possui reservatório próprio (água: poço; mina; caminhão pipa); } & 0 & Não Conforme \\
\hline \multicolumn{2}{|c|}{$\begin{array}{l}\text { 3) Reservatório de água dotados de tampa, satisfatória condição de uso, livre de } \\
\text { vazamentos, infiltrações e descascamentos; }\end{array}$} & 10 & Conforme \\
\hline \multicolumn{2}{|c|}{ 4) Apropriada frequência de higienização do reservatório de água; } & 0 & Não Conforme \\
\hline \multicolumn{2}{|c|}{$\begin{array}{l}\text { 5) Existência de registros da higienização do reservatório e/ou comprovante de } \\
\text { execução do serviço em caso de terceirizadas; }\end{array}$} & 0 & Não Conforme \\
\hline \multicolumn{2}{|c|}{ 6) Potabilidade da água a partir de laudos laboratoriais; } & 0 & Não Conforme \\
\hline \multicolumn{2}{|c|}{ 7) Controle de potabilidade realizado por técnico comprovadamente capacitado. } & 0 & Não Conforme \\
\hline Resultado Ideal: 70 pontos $\mid 100 \%$ & Resultado Real: & $20 \mid 28,58 \%$ & Ruim \\
\hline
\end{tabular}
Fonte: Própria (2020).

Tal resultado mostra-se em desacordo com a legislação, pois, para a RDC 275/2002, a água utilizada para a manipulação dos alimentos deve ser potável e os reservatórios devem estar em ótimas condições de conservação (BRASIL, 2002). De forma similar à realidade encontrada no Mercado de Carnes do Ver-o-Peso, Rodrigues et al. (2017), no Município de Bom Jesus (PI), identificaram que a água que abastecia os estabelecimentos comercializadores de carne era de origem pública, porém nenhum dos reservatórios apresentava cuidados higiênicos e todos se encontravam em péssimas condições. Segundo dados do Ministério da Saúde, em 2018, foram notificados 503 surtos de doenças veiculadas por alimentos, em que 29,9\% incriminou a água como um dos alimentos de maior suspeita (BRASIL, 2018).

Ao avaliar o item "2 - Controle integrado de pragas", obteve-se o resultado de 50\% (25 pontos), sendo considerado "Ruim" (Tabela 4). Apesar de o mercado apresentar ralos fechados, não estavam em boas condições de conservação e havia acúmulo de lixo, o qual provocava a 
sua obstrução e prejudicava a sua eficiência (Figura 2). Conforme a administração do espaço, constantemente se faz uso de produtos químicos para inibir e/ou acabar com as pragas inclusive essa prática de dedetização conta com comprovantes de execução disponibilizados pela empresa responsável pelo serviço. Todavia, evidenciou-se que as portas e as janelas não são ajustadas às patentes e não dispõem de proteção inferior. Ademais, não são adotadas outras medidas preventivas/corretivas além da dedetização para de inibir, de não abrigar e/ou proliferar pragas.

Tabela 4. Aspectos avaliados referente ao controle integrado de pragas do mercado

\begin{tabular}{|c|c|c|}
\hline II - CONTROLE INTEGRADO DE PRAGAS & Pontuação & Resultado \\
\hline 8) Os ralos e grelhas são sifonados e fechados; & 5 & Parcialmente \\
\hline $\begin{array}{l}\text { 9) As portas são ajustadas aos batentes, apresentam proteção na parte inferior } \\
\text { contra entrada de insetos e roedores e possuem mola; }\end{array}$ & 0 & Não Conforme \\
\hline $\begin{array}{l}\text { 10) Adota-se medidas preventivas/corretivas para não atrair, abrigar e/ou } \\
\text { proliferar pragas; }\end{array}$ & 0 & Não Conforme \\
\hline 11) Faz uso de produtos químicos para a inibir e/ou acabar com as pragas; & 10 & Conforme \\
\hline $\begin{array}{l}\text { 12) Em caso de adoção do controle químico, existência de comprovante de } \\
\text { execução de expedido por empresa especializada; }\end{array}$ & 10 & Conforme \\
\hline Resultado Ideal: 50 pontos $\mid 100 \%$ & $25 \mid 50 \%$ & Ruim \\
\hline
\end{tabular}

Fonte: Própria (2020).

Figura 2. Ralos do mercado

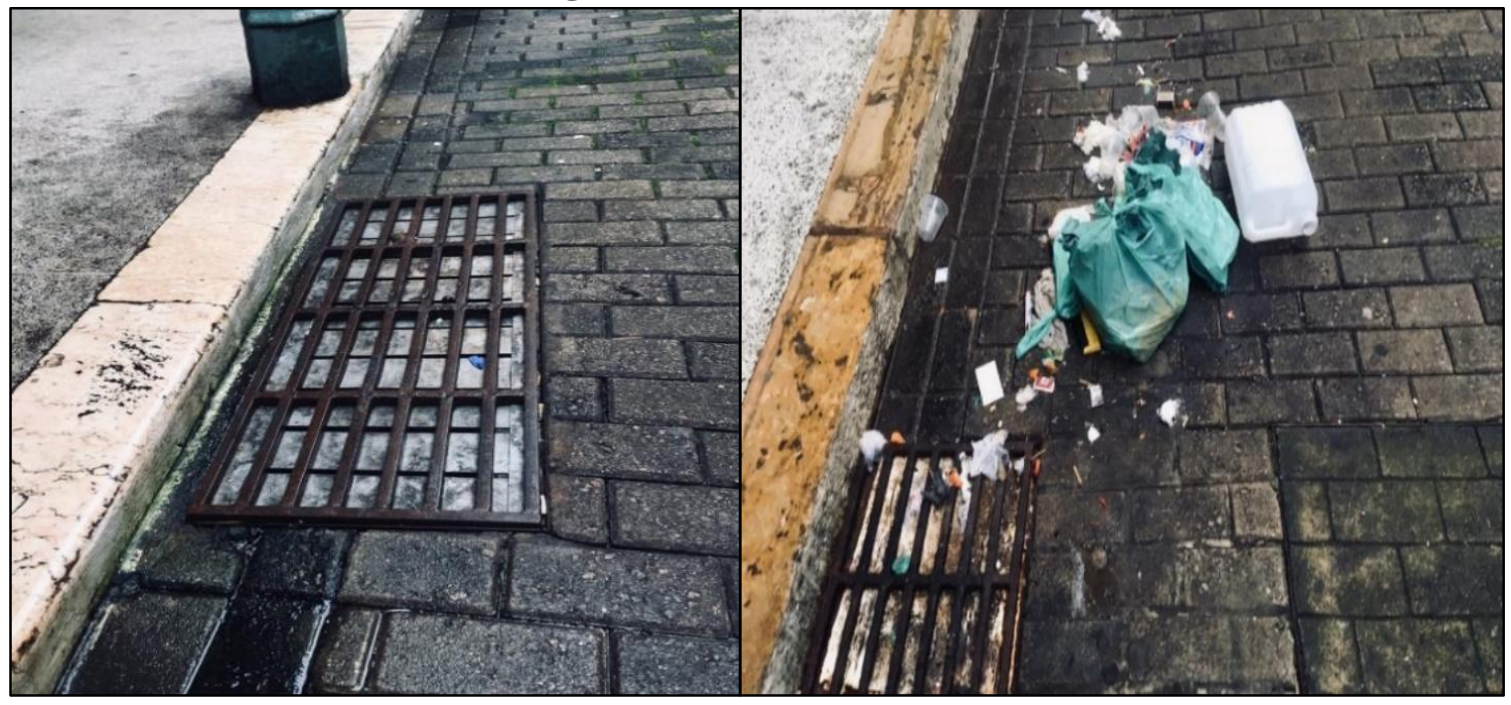

Fonte: Própria (2020).

Segundo a RDC 275/2002, o controle integrado de vetores e pragas urbanas 
[...] devem contemplar as medidas preventivas e corretivas destinadas a impedir a atração, o abrigo, o acesso e ou a proliferação de vetores e pragas urbanas. No caso da adoção de controle químico, o estabelecimento deve apresentar comprovante de execução de serviço fornecido pela empresa especializada contratada, contendo as informações estabelecidas em legislação sanitária específica (BRASIL, 2002, p. 7).

Nada distante, no Mercado Municipal de Icoaraci, Distrito de Belém, de acordo com a pesquisa de Rosa et al. (2019), sendo semelhante em virtude dos mercados estarem localizados na mesma cidade, enfrenta uma realidade ainda mais grave, devido ao fato do espaço estrutural se apresentar desconforme em todos os itens correspondentes à controle de pragas. Segundo os autores mencionados, o mercado não possuía controle de pragas e as caixas de gordura eram mantidas sem qualquer cobertura de proteção, propiciando a entrada de insetos e pragas que poderiam contaminar os alimentos comercializados.

Os locais em que há a presença de comerciantes e consumidores devem dispor de banheiros e/ou vestiários com o objetivo de confortar o público quando necessário para fins de necessidades pessoais, mas para isso, deve-se apresentar em bom estado estrutural e de conservação. Sendo assim, o quesito "3 - Sanitários e vestiários” ao ser avaliado, apresentou $70 \%$ de conformidade (Tabela 5), sendo considerado como "Bom", tendo em vista que apresentou conformidade nos seguintes quesitos: existiam banheiros para uso dos feirantes e frequentadores do mercado; os sanitários possuíam tampa; os banheiros contavam com pias para a higienização das mãos e havia uma frequente coleta de lixo.

Ademais, entre as conformidades parciais estão a distância dos banheiros em relação à área de produção e de manipulação de alimentos do mercado, o bom estado de uso (com as paredes e pisos apresentando bom estado de conservação), a iluminação e a disposição de produtos de higienização (sabão líquido e toalhas descartáveis). Diante disso, nas observações constatou-se que o mercado atende às recomendações da RDC 275/2002 do Ministério da Saúde, a qual exige que os estabelecimentos contenham banheiros e/ou vestiários adequados e em bom estado de conservação, a fim de garantir um bom uso do local e garantir higienização adequada (BRASIL, 2002). Entretanto, em trabalho semelhante, Santos et al. (2016) declararam em sua pesquisa referente a um mercado de peixes localizado na Zona Leste de Teresina (PI), que mesmo com o distanciamento dos banheiros das áreas de manipulação e armazenamento, a estrutura dos banheiros encontravam-se em condições desapropriadas de uso, tendo em vista que "[...] não dispõem de mictórios, nem torneiras e portas com acionamento e fechamento automático, respectivamente. Não possuem ducha em número suficiente, estão com iluminação, ventilação e estado de conservação inadequados". 
Tabela 5. Aspectos avaliados referente ao item sanitários e vestiários do mercado

\begin{tabular}{|c|c|c|}
\hline III - SANITÁRIOS E VESTIÁRIOS & Pontuação & Resultado \\
\hline 13) Apresenta banheiros para uso dos feirantes e frequentadores & 10 & Conforme \\
\hline $\begin{array}{l}\text { 14) Se existente, apresenta-se longe das áreas de produção e/ou manipulação } \\
\text { de alimentos presentes no Mercado }\end{array}$ & 5 & Parcialmente \\
\hline $\begin{array}{l}\text { 15) Pisos e paredes adequados apresentando satisfatório estado de } \\
\text { conservação. }\end{array}$ & 5 & Parcialmente \\
\hline 16) O compartimento encontra-se em bom estado de uso & 5 & Parcialmente \\
\hline 17) Os vasos sanitários possuem assento com tampa & 10 & Conforme \\
\hline 18) Iluminação e ventilação adequadas & 5 & Parcialmente \\
\hline 19) Dispõe de lixeiras com pedais para o descarte dos papéis servidos & 5 & Parcialmente \\
\hline 20) Possui pia para a higienização das mãos & 10 & Conforme \\
\hline $\begin{array}{l}\text { 21) Dispõe de produtos de higiene e assepsia (sabão líquido, álcool, toalhas } \\
\text { descartáveis) }\end{array}$ & 5 & Parcialmente \\
\hline 22) Coleta frequente de lixo & 10 & Conforme \\
\hline Resultado Ideal: 100 pontos $\mid 100 \%$ & $70 \mid 70 \%$ & Bom \\
\hline
\end{tabular}

Fonte: Própria (2020).

Podendo ser considerado um dos mais importantes quando se trata do Mercado Bolonha, o item "4 - Instalações e edificações", após a análise dos dados, apresentou 75\% de conformidades, sendo considerado "Excelente". Como mostra a Tabela 6, em que cinco dos oito itens avaliados conseguiram a nota máxima (10 pts.), sendo estes: o mercado possuía acesso livre, independente e sem comunicação com residências; o local possuía ventilação suficiente para proporcionar conforto térmico, tendo em vista que o mercado é um local aberto (Figura 3). Além disto, o piso apresentava caimento direto para os ralos (observado anteriormente na Figura 2), o sistema de esgoto juntamente com as caixas de esgoto estava livre de vazamentos, odores e apresentavam-se vedadas e em bom estado de conservação, estando também fora da área de manipulação dos alimentos (Figura 4).

Conforme a RDC 216/2004, as instalações devem ser projetadas com o objetivo de facilitar os processos de limpeza, desinfecção e as operações de manutenção. No mais, a resolução exige que "O acesso às instalações deve ser controlado e independente, não comum a outros usos" (BRASIL, 2004, s. p.). Ao analisarem as condições estruturais do Mercado Público do Município de Parnaíba (PI), Costa et al. (2017) declaram em seu estudo que o espaço estava sujo, com rejeitos espalhados, lixo exposto, esgoto aberto e exalando odor desagradável 
- situação bastante comum em diversos mercados e feiras populares pelo Brasil.

Tabela 6. Aspectos avaliados referente às instalações e edificações do mercado

\begin{tabular}{|c|c|c|c|}
\hline \multicolumn{2}{|c|}{ IV - INSTALAÇÕES E EDIFICAÇÕES DO MERCADO } & Pontuação & Resultado \\
\hline \multicolumn{2}{|c|}{$\begin{array}{l}\text { 23) O Mercado tem acesso livre, independente e sem comunicação direta } \\
\text { com residências }\end{array}$} & 10 & Conforme \\
\hline \multicolumn{2}{|c|}{ 24) O local possui ventilação suficiente para proporcionar conforto térmico } & 10 & Conforme \\
\hline \multicolumn{2}{|c|}{ 25) Estão livres de sucata, lixo e animais } & 5 & Parcialmente \\
\hline \multicolumn{2}{|c|}{ 26) O piso apresenta caimento direto para os ralos } & 10 & Conforme \\
\hline \multicolumn{2}{|c|}{ 27) As instalações elétricas apresentam-se em bom estado de conservação } & 5 & Parcialmente \\
\hline \multicolumn{2}{|c|}{ 28) O sistema de esgoto está livre de vazamentos e odores } & 10 & Conforme \\
\hline \multicolumn{2}{|c|}{$\begin{array}{l}\text { 29) A caixa de esgoto está presente fora da área das manipulações, e está } \\
\text { vedada }\end{array}$} & 10 & Conforme \\
\hline \multicolumn{2}{|c|}{$\begin{array}{l}\text { 30) O mercado possui local próprio e adequado para o armazenamento } \\
\text { externo do lixo, protegido de chuva, sol, acesso de animais domésticos e } \\
\text { roedores e livre de odores }\end{array}$} & 0 & Não Conforme \\
\hline Resultado Ideal: 80 pontos $100 \%$ & Resultado Real: & $60 \mid 75 \%$ & Excelente \\
\hline
\end{tabular}

Fonte: Própria (2020).

Figura 3. Corredor principal do mercado

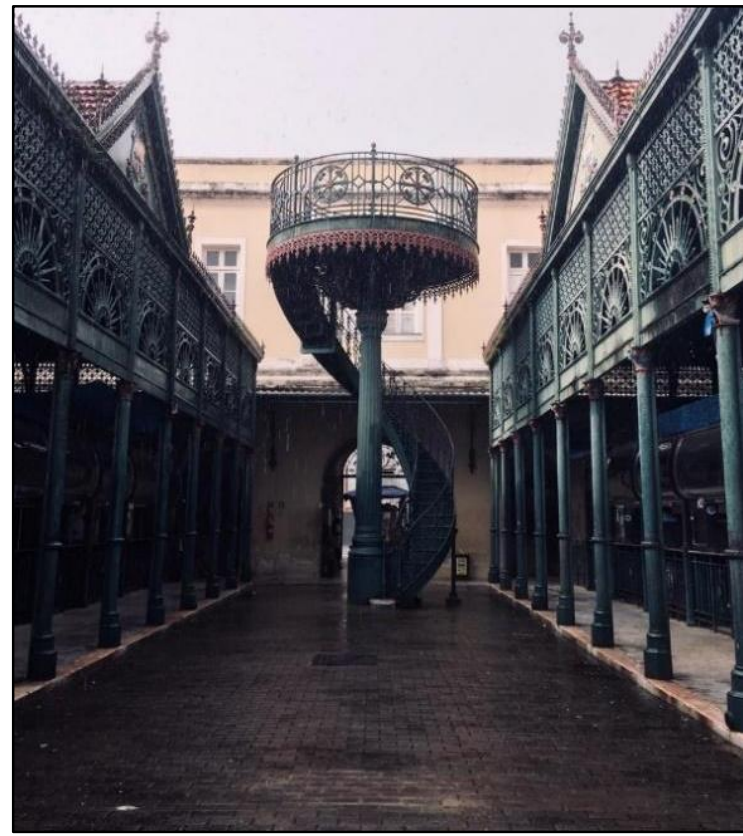

Fonte: Própria (2020). 
Figura 4. Caixas de gordura e esgoto

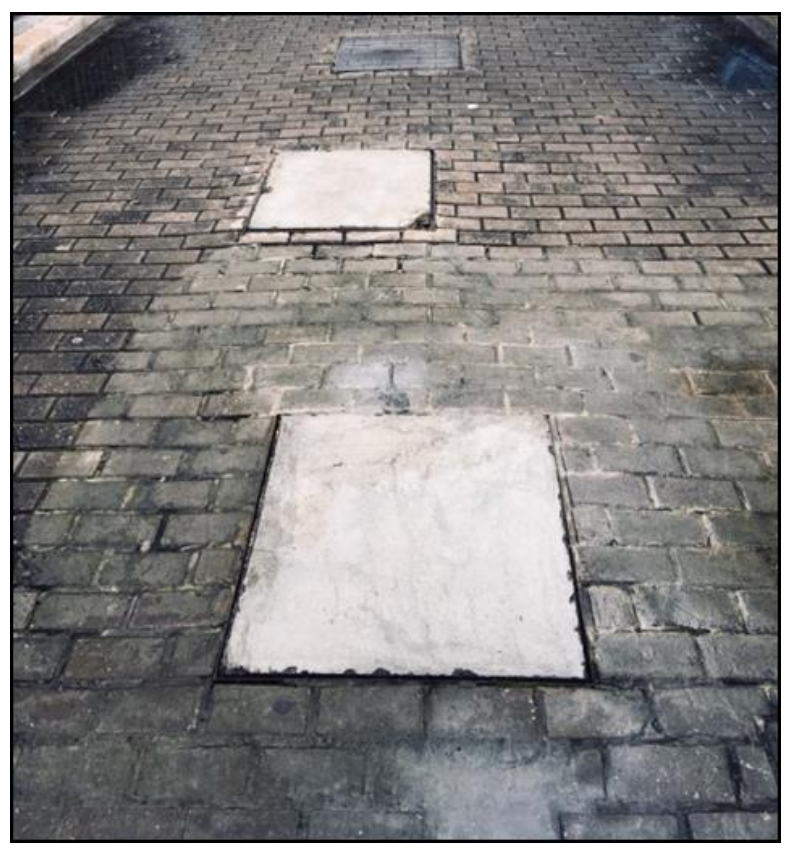

Fonte: Própria (2020).

No entanto, apesar de esse item ter alcançado um excelente resultado, ainda houveram conformidades parciais, ao observar que: o mercado não estava livre de sucata, lixo e animais. Em relação às instalações elétricas, quando observado no mercado em geral, a fiação não está aparente, no entanto, é importante destacar que os espaços destinados a venda de carne bovina, é aparente a exposição de fiação improvisada, indo de encontro ao que determina a RDC 216/2004 (BRASIL, 2004), quando menciona que as instalações elétricas devem estar embutidas e protegidas. Segundo alguns feirantes e a Administração do Mercado, como a energia não é forte o suficiente para alimentar a dos pontos de venda, os balcões suspensos implantados na reforma do mercado em 2007 nunca funcionaram e atualmente servem apenas de depósito para mantimentos, conforme a Figura 5. À vista disso, os feirantes utilizam pedaços de ferro enferrujado para fazer a exposição dos alimentos aos consumidores.

Consoante dispõe a RDC 216/2004 (BRASIL, 2004), os balcões devem utilizados apenas como local de armazenamento de utensílios, assim como precisam ser mantidos em bom estado de conservação e devem passar por periódicas operações de limpeza e desinfecção. Esse cenário se aproxima da pesquisa realizada por Costa et al. (2013), que evidenciaram péssimas condições higiênico-sanitárias e estruturais da edificação de minimercados de Recife (PE), bem como equipamentos, móveis e utensílios se mostravam insatisfatórios, uma vez que não atendiam aos critérios exigidos pela legislação aplicável. 
Figura 5. Balcão frigorífico que não funciona, presença de sucata e fiação exposta nos pontos de venda de carne bovina do Mercado Bolonha

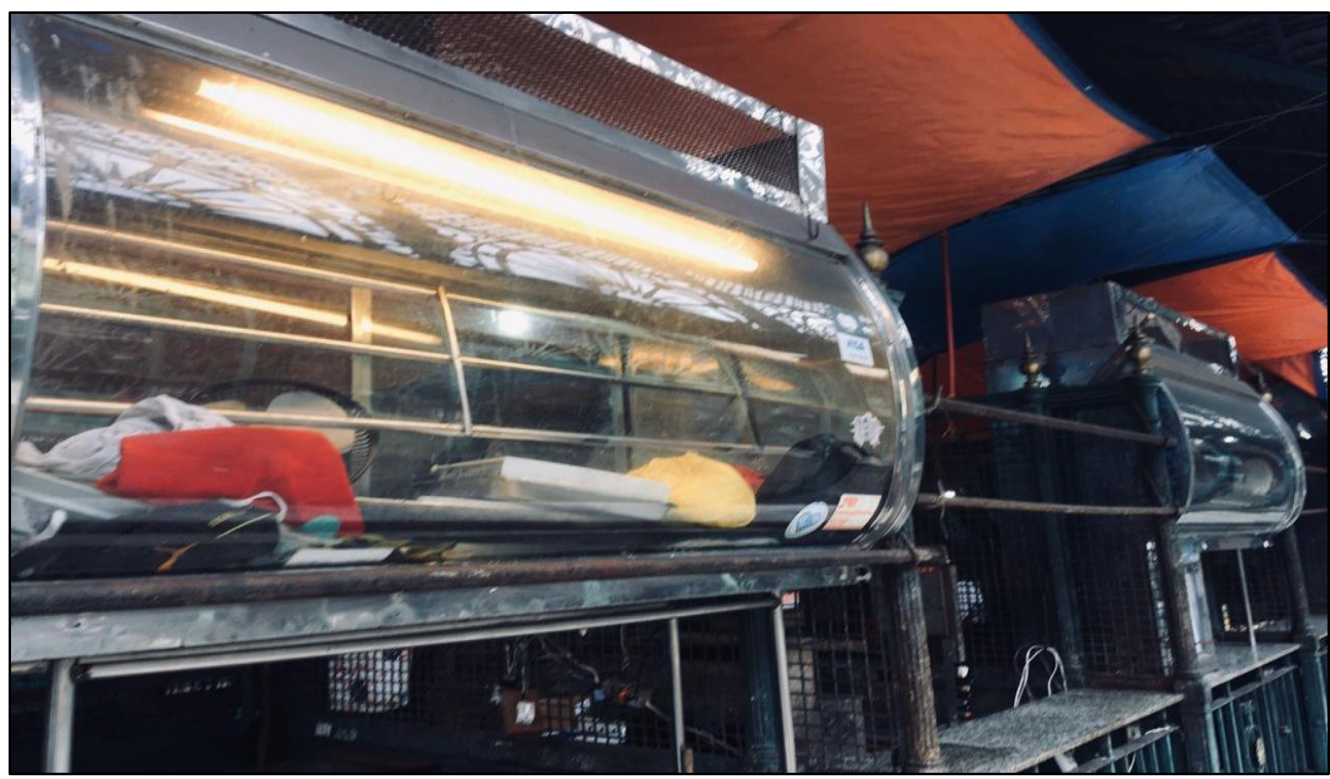

Fonte: Própria (2020).

\section{Conclusões}

No transcorrer desta investigação acerca das condições higiênico-sanitárias do Mercado Francisco Bolonha, a partir dos quesitos avaliados, pôde-se evidenciar que as condições estruturais do mercado, acrescidas do mau cuidado por parte das autoridades responsáveis e dos comerciantes, conformam um espaço com muitas inadequações para o comércio e para a manipulação de alimentos, uma vez que as condições atuais do mercado podem propiciar a contaminação e a disseminação de DVAs. Destarte, é essencial ofertar cursos de capacitação sobre Boas Práticas de Manipulação, a fim de que os comerciantes possam melhorar as condições de trabalho e, consequentemente, ofertar alimentos com melhor qualidade.

\section{Referências}

BRASIL. Resolução n⿳ 216, de 15 de setembro de 2004. Dispõe sobre o Regulamento Técnico de Boas Práticas para serviços de Alimentação. Diário Oficial da União - DOU da República Federativa do Brasil. Agência Nacional de Vigilância Sanitária. Brasília, DF, 15 set. 2004. Disponível http://portal.anvisa.gov.br/documents/33916/388704/RESOLU\%25C3\%2587\%25C3\%2583O

RDC\%2BN\%2B216\%2BDE\%2B15\%2BDE\%2BSETEMBRO\%2BDE\%2B2004.pdf/237014 96-925d-4d4d-99aa-9d479b316c4b. Acesso em: 08 abr. 2019.

BRASIL. Resolução n⿳ 275, de 21 de outubro de 2002. Dispõe sobre o Regulamento Técnico de Procedimentos Operacionais Padronizados aplicados aos Estabelecimentos Produtores/Industrializadores de Alimentos. Diário Oficial da União - DOU da República Federativa do Brasil. Agência Nacional de Vigilância Sanitária. Brasília, DF, 21 out. 2002. Disponível

em: 
http://portal.anvisa.gov.br/documents/10181/2718376/RDC_275_2002_COMP.pdf/fce9dac0ae57-4de2-8cf9-e286a383f254. Acesso em: 07 abr. 2019.

BRASIL. Lei $\mathbf{n}^{\mathbf{0}}$ 6.437, de 20 de agosto de 1977 [Lei de infrações à legislação sanitária]. Configura infrações à legislação sanitária federal, estabelece as sanções respectivas, e dá outras providências. Diário Oficial da União - DOU da República Federativa do Brasil. Presidência da República. Brasília, DF, 20 ago. 1977 Disponível em: http://www.planalto.gov.br/ccivil_03/LEIS/L6437.htm. Acesso em: 08 abr. 2019.

BRASIL. Surtos de doenças transmitidas por alimentos no Brasil: informe 2018. Brasília (DF): Ministério da Saúde, 2018.

RODRIGUES, A. A. et al. Aspectos higiênico-sanitários de estabelecimentos comercializadores de carnes no município de Bom Jesus-PI. Revista Brasileira de Higiene e Sanidade Animal, v. 11, n. 1, p. 94-103, 2017.

COSTA, J. et al. Condições higiênico-sanitárias e físico-estruturais da área de manipulação de carne in natura em minimercados de Recife (PE), Brasil. Arquivos do Instituto Biológico, São Paulo, v. 80, n. 3, p. 352-358, 2013.

COSTA, M. C. et al. Condições higiênico-sanitárias da carne bovina comercializada em um mercado público do Piauí. Segurança Alimentar e Nutricional, Campinas, v. 24, n. 1, p. 1-8, 2017.

SILVA, L. H. R. Mercado Bolonha: patrimônio arquitetônico e lócus de práticas culturais comerciais em Belém do Pará. 2018. 118 f. Dissertação (Mestrado em Arquitetura e Urbanismo) - Instituto de Tecnologia, Universidade Federal do Pará, Belém, 2018.

MATOS, J. C. et al. Condições higiênico-sanitárias de feiras livres: uma revisão integrativa. Revista Eletrônica Gestão \& Saúde, Brasília, v. 6, n. 3, p. 2884-2893, 2015.

OLIVEIRA, F. et al. Cadeia produtiva da carne bovina no Brasil. Revista Interação Interdisciplinar, Mineiros, v. 1, n. 1, p. 229-244, 2017.

REIS, R. M. Qualidade de carne bovina moída in natura comercializada em Manaus, AM. 2019. 60 f. Dissertação (Mestrado em Ciência Animal) - Faculdade de Ciências Agrárias, Universidade Federal do Amazonas, Manaus, 2019.

ROSA, M. Y. O. et al. O risco sanitário na comercialização de alimentos em um mercado público da Amazônia: um estudo de caso em Belém (PA). Scientia Plena, Aracaju, v. 15, n. 10, p. 1-7, 2019.

SANTOS, E. H. B. et al. Avaliação das Condições Higiênico-Sanitárias no Comércio de Pescados em um Mercado do Peixe. Journal of Health Sciences, Londrina, v. 18, n. 3, p. 151$158,2016$.

SÃO PAUlO (Município). Portaria no 2619, de 6 de dezembro de 2011, Dispõe sobre o Regulamento de Boas Práticas e de Controle de condições sanitárias e técnicas das atividades relacionadas à importação, exportação, extração, produção, manipulação, beneficiamento, acondicionamento, transporte, armazenamento, distribuição, embalagem, reembalagem, 
fracionamento, comercialização e uso de alimentos, águas minerais e de fontes, bebidas, aditivos e embalagens para alimentos. Secretaria Municipal de Saúde. São Paulo, SP, 6 dez. 2011.

Disponível

em: https://www.prefeitura.sp.gov.br/cidade/secretarias/upload/chamadas/portaria_2619_1323696 514.pdf. Acesso em: 07 abr. 2019.

SILVA, I. S.; CASTRO, E. M. R. Interações rural-urbano: a sociobiodiversidade e o trabalho em portos, feiras e mercados de Belém, Pará. Novos Cadernos NAEA, Belém, v. 16, n. 1, p. 109-126, 2013. 